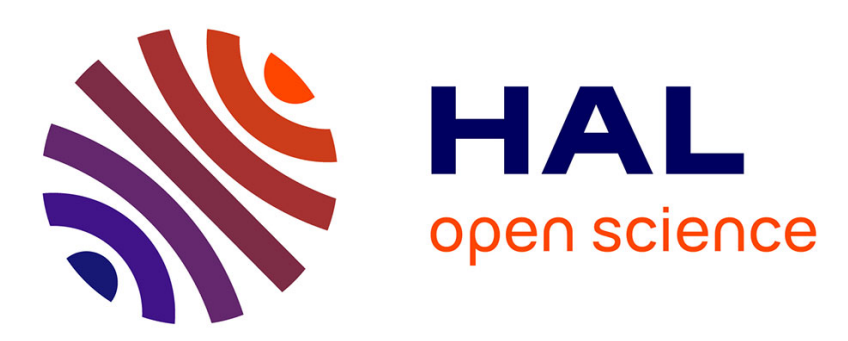

\title{
Tunnelling spectra in (TMTSF)2ClO4/I/Pb junctions
}

A. Fournel, B. Oujia, J.P. Sorbier

\section{To cite this version:}

A. Fournel, B. Oujia, J.P. Sorbier. Tunnelling spectra in (TMTSF)2ClO4/I/Pb junctions. Journal de Physique Lettres, 1985, 46 (9), pp.417-424. 10.1051/jphyslet:01985004609041700 . jpa-00232537

\section{HAL Id: jpa-00232537 https://hal.science/jpa-00232537}

Submitted on 1 Jan 1985

HAL is a multi-disciplinary open access archive for the deposit and dissemination of scientific research documents, whether they are published or not. The documents may come from teaching and research institutions in France or abroad, or from public or private research centers.
L'archive ouverte pluridisciplinaire HAL, est destinée au dépôt et à la diffusion de documents scientifiques de niveau recherche, publiés ou non, émanant des établissements d'enseignement et de recherche français ou étrangers, des laboratoires publics ou privés. 
Classification

Physics Abstracts

$72.15 \mathrm{~N}-74.10-74.50$

\title{
Tunnelling spectra in (TMTSF) $)_{2} \mathrm{ClO}_{4} / \mathrm{I} / \mathrm{Pb}$ junctions
}

\author{
A. Fournel, B. Oujia and J. P. Sorbier \\ Département d'Electronique, Université de Provence, 13397 Marseille Cedex 13, France
}

(Reçu le 20 août 1984, révisé le 1er février 1985, accepté le 14 mars 1985)

\begin{abstract}
Résumé. - L'effet tunnel permet une observation directe de toute variation de densité d'états au niveau de Fermi des électrodes en présence. Cependant certaines anomalies peuvent être présentes et conduire à des interprétations ambiguës. Pour essayer d'écarter toute ambiguïté, nous avons réalisé des jonctions (TMTSF) ${ }_{2} \mathrm{ClO}_{4} / \mathrm{I} / \mathrm{Pb}$, le plomb servant de test. Dans les bonnes jonctions, un effet particulier est mis en évidence lorsque la température diminue et ce pour une température $T>T_{\mathrm{c}}$ du (TMTSF) ${ }_{2} \mathrm{ClO}_{4}$. Cet effet pourrait s'expliquer par l'existence de domaines fluctuatifs supraconducteurs unidimensionnels. Nos travaux en cours (c.a.d. suivi de la courbe tunnel lorsque la température varie de $T>T_{\mathrm{c}}$ du (TMTSF) ${ }_{2} \mathrm{ClO}_{4}$ à $T<T_{\mathrm{c}}$ ) devraient nous permettre de savoir si l'effet est bien dû au conducteur organique.
\end{abstract}

\begin{abstract}
By using the tunnelling effect, we can observe all density variations around the Fermi level of the junction electrodes. Nevertheless, zero bias anomalies may induce ambiguous interpretations. With the aim to getting rid of all ambiguity, we have realized (TMTSF) ${ }_{2} \mathrm{ClO}_{4} / \mathrm{I} / \mathrm{Pb}$ devices, the lead serving as a quality test. In the best junctions, a particular effect is observed when the temperature decreases, for temperatures $T$ above the $T_{\mathrm{c}}$ of (TMTSF) ${ }_{2} \mathrm{ClO}_{4}$. This effect might be due to the occurrence of 1-D fluctuating superconductivity domains. But we cannot be sure that there is no zero bias anomaly. Our future work (observation of the tunnelling curve when the temperature varies from $T>T_{\mathrm{c}}$ of (TMTSF) ${ }_{2} \mathrm{ClO}_{4}$ to $T<T_{\mathrm{c}}$ ) should allow us to see if the observed effect described in this paper is actually due to the organic conductor.
\end{abstract}

\section{Introduction.}

Of all the organic conductors studied to date, the most interesting are the (TMTSF) ${ }_{2} \mathrm{X}$ salts. For these materials one question is presently being discussed, namely are the low temperature properties due to monodimensionality or to multidimensionality of the Fermi surface. From many experiments, the Orsay Group have presented a model [1] according to this first hypothesis, in which precursor effects of the superconductive state exist in a range of temperature much above the temperature where the long range order (three-dimensional superconductivity) is obtained. These precursor effects should be manifested by a $N(E)$ variation around the Fermi level $\left(E_{\mathrm{F}}\right)$, i.e. by a partial condensation or pseudo gap.

With the aim of observing this condensation, we have used the tunnelling effect which is a very sensitive method for the observation of such phenomena. It is well known that the derivate $\mathrm{d} I / \mathrm{d} V$ of the $I=f(V)$ characteristic of a $\mathrm{S} / \mathrm{I} / \mathrm{N}$ junction is directly proportional to the density of states $N(E)$ in a superconductor $\mathrm{S}$ as shown in figure 1a (for experimental reasons we have 
a)

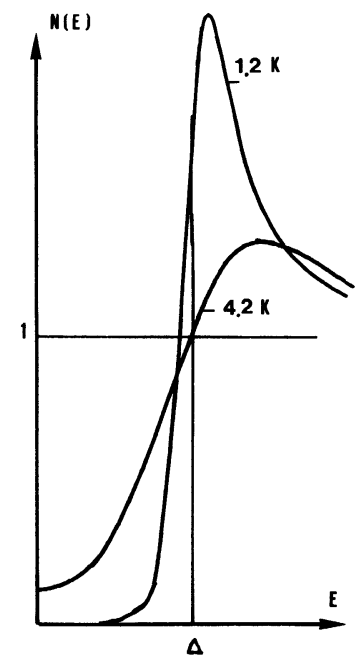

b)

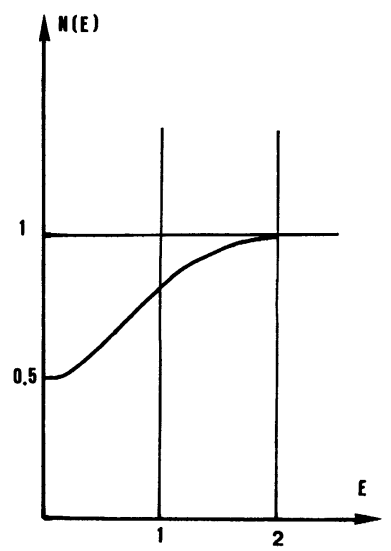

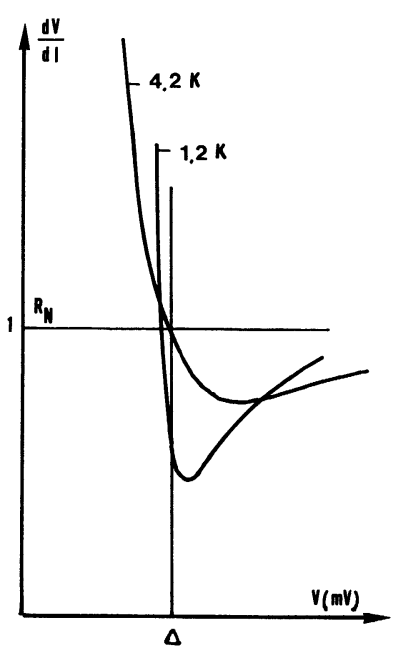

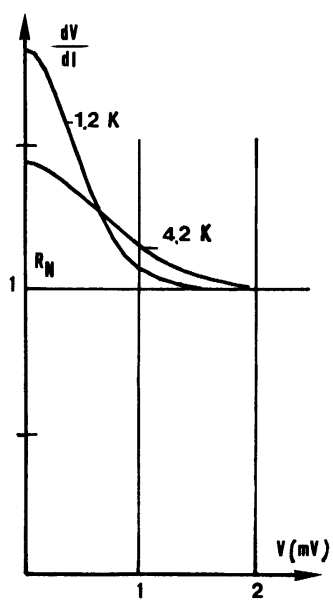

Fig. 1. - (a) We have drawn the B.C.S. superconductive density of states $N(E)$ at $4.2 \mathrm{~K}$ and $1.2 \mathrm{~K}$ (left side), and, at the same temperatures the behaviour of $\mathrm{d} V / \mathrm{d} I$ versus bias voltage. (b) Describes the case where the density of states presents only a partial condensation (left side), which does not depend on temperature. On the right side we have drawn the theoretical tunnelling curves $\mathrm{d} V / \mathrm{d} I$ versus bias voltage at $4.2 \mathrm{~K}$ and $1.2 \mathrm{~K}$.

drawn systematically $\mathrm{d} V / \mathrm{d} I)$. With $\mathrm{X} / \mathrm{I} / \mathrm{M}$ junctions, where $\mathrm{X}$ is a material which presents a partial condensation around the Fermi level and where $M$ is a metal in a normal state, the variation $\mathrm{d} V / \mathrm{d} I(V)$ as shown in picture $1 \mathrm{~b}$, has a shape such as those induced by zero bias anomalies. How can we be sure that we have a good tunnelling effect ? One way of removing this ambiguity is to use in place of a metal $\mathrm{M}$, a superconductor $\mathrm{S}$ having a very well known tunnelling spectrum. We have chosen lead which is a strong coupling superconductor with a very particular electronphonon interaction which is easily observable [2]. In consequence we call "good tunnelling junction " all junctions which exhibit not only a resistance peak induced by the superconductive gap but also the phonon-electron interaction which is a small effect of the order of a few per cent of $R_{\mathrm{N}}\left(R_{\mathrm{N}}\right.$ is the resistance of the junction at zero bias when the superconductive electrode is in the normal state). We have successfully used this criterion in $\mathrm{NbSe}_{3} / \mathrm{I} / \mathrm{Pb}$ junctions to show that a partial condensation (pseudo gap) starts at $59 \mathrm{~K}$ and exists below [3]. 


\section{Experimental results.}

Tunnelling spectra are obtained by a standard technique. We present different spectra which may be classified into 3 cases :

Case 1. - A first case of spectra is shown in figure 2. It is very unusual, because we see a widening of the superconductive gap when the temperature is decreased. The widening is near $0.6 \mathrm{mV}$ when the temperature is varying from $4.2 \mathrm{~K}$ to $1.2 \mathrm{~K}$. The ratio of the amplitude of peak at null bias voltage to $R_{\mathrm{N}}$ at $4.2 \mathrm{~K}$ is of the order of 6 (this value is obtained in a good tunnelling $\mathrm{AsGa} / \mathrm{Pb}$ junction at this temperature). As shown by figure 3, the electron-phonon interaction is clearly seen but the gap edges singularities are removed. When a magnetic field is applied to these junctions, a structure is always present even with a magnetic field equal to $3 \mathrm{kG}\left(H>H_{\mathrm{c}} \mathrm{Pb}\right)$. This is shown in the insert of figure 2 . This structure decreases slightly when $H$ increases.

Figure 6 describes the $\mathrm{d} V / \mathrm{d} I$ comportment, at null bias voltage, versus temperature. The decrease of $\mathrm{d} V / \mathrm{d} I(V=0)$ with temperature comes from that at high temperature (above $100 \mathrm{~K})$, the resistance of (TMTSF) ${ }_{2} \mathrm{ClO}_{4}$ represented by $R_{1}$ and $R_{2}$ in the insert of figure 6 is of the same order as the junction resistance $R_{\mathrm{J}}$. This is not important in the injection loop because we use a constant current. But in the detection loop we measure the voltage across $R_{\mathrm{J}}$ plus $R_{2}$. At low

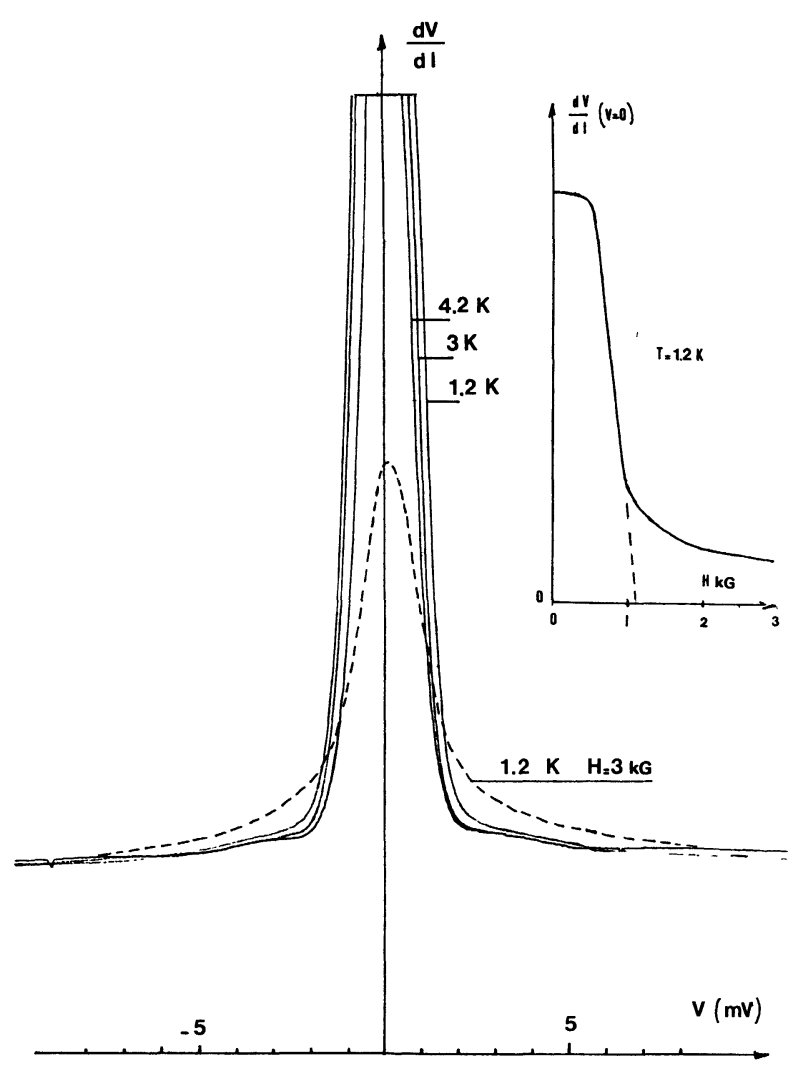

Fig. 2. - This figure describes the first case. The ratio of the maximum amplitude at $4.2 \mathrm{~K}$ to $R_{\mathrm{N}}$ is near 6 . The phonon-electron interaction is visible without amplification and the widening of superconductive gap is clearly seen. The insert shows the dependence of the maximum versus magnetic field at $1.2 \mathrm{~K}$. A structure remains in place which depends slightly on the magnetic field. 


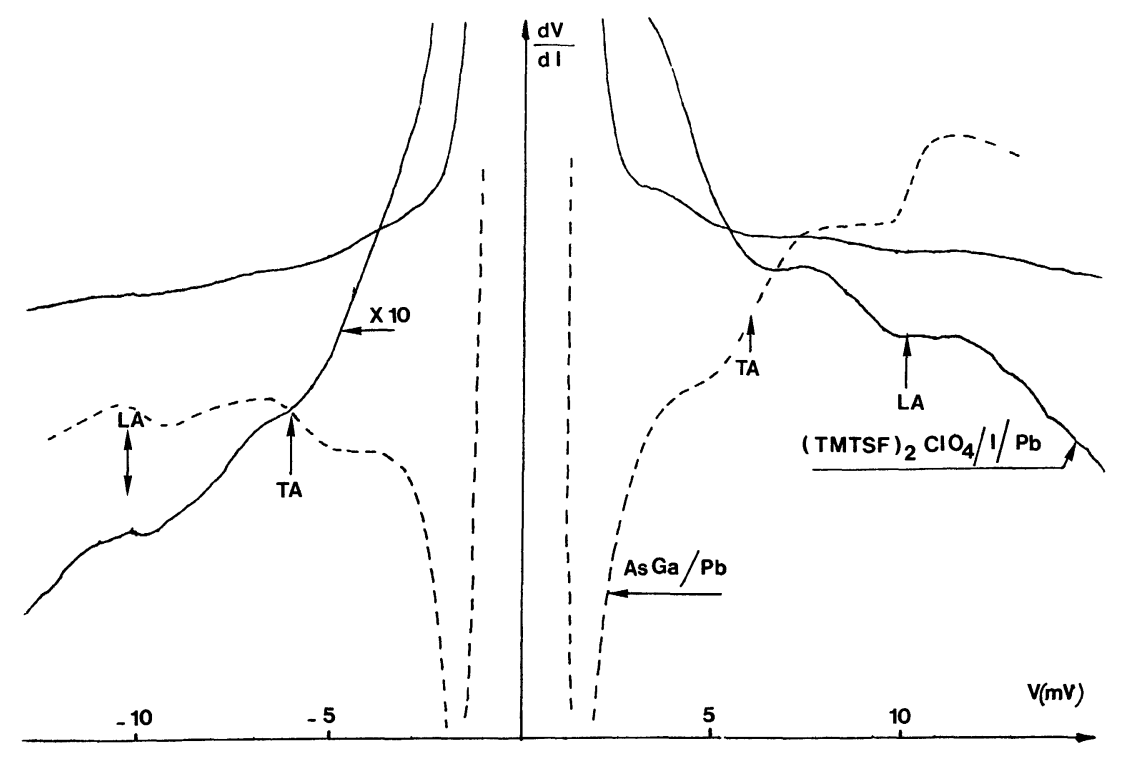

Fig. 3. - We have compared the phonon-electron interaction between (TMTSF) ${ }_{2} \mathrm{ClO}_{4} / \mathrm{I} / \mathrm{Pb}$ and $\mathrm{AsGa} / \mathrm{Pb}$ junctions. TA and LA phonon energies are those measured with $\mathrm{AsGa} / \mathrm{Pb}$ junctions.

temperature this disavantage disappears because the resistance of (TMTSF) ${ }_{2} \mathrm{ClO}_{4}$ falls and $R_{\mathrm{J}} \gg R_{2}$. We observe a stabilization of $\mathrm{d} V / \mathrm{d} I(V=0)$ when $T<20 \mathrm{~K}$. The break which appears between 30 and $25 \mathrm{~K}$ [4] is induced by a structural phase transition [5] leading to a relaxed state [6].

Case 2. - Figure 4 represents the second case of spectra. The phonon-electron interaction is barely visible and the evolution of the resistivity peak is still different from that of a classical $\mathrm{M} / \mathrm{I} / \mathrm{S}$ junction. Indeed there is a small broadening around the turning points since we measure $3.1 \mathrm{mV}$. The application of a magnetic field up to $3 \mathrm{kG}$ destroys all the superconductivity.

Case 3. - We have the classical case of $M / I / S$ junctions and the gap value is that of lead i.e. $2 \Delta(T)=2.7 \mathrm{mV}$. At higher energies the interaction phonon-electron is not visible and when a magnetic field up to $1.5 \mathrm{kG}$ is applied all the superenductivity is destroyed. We may add that the ratio of peak magnitude at null voltage to $R_{\mathrm{N}}$, at $4.2 \mathrm{~K}$, is near 3.5 ; this value is rather small compared to the theoretical value ( $\simeq 8$ for the same temperature). Finally, an increase of $\mathrm{d} V / \mathrm{d} I$ $(V=0)$ appears near $90 \mathrm{~K}$ (the threshold of this increase varies from $100 \mathrm{~K}$ to $70 \mathrm{~K}$ depending on the junction) (Fig. 6).

\section{Discussion.}

Case 1. - The amplitude $\mathrm{d} V / \mathrm{d} I(V=0)$ is stabilized from $25 \mathrm{~K}$ to $7.2 \mathrm{~K}$, the electron-phonon interaction is well observed, a very particular behaviour of the lead superconductive gap when the temperature is decreasing is observed, and finally, in a magnetic field a structure subsists.

It is well known that a not well defined barrier leads to a modification of the ideal tunnelling curve near zero bias vaiues. If the modification of the lead tunnelling spectra, that we observe, is due to such an anomaly, it must appear over a small energy range (less than $4 \mathrm{meV}$ ), because the electron-phonon interaction is well seen, and for $T<7 \mathrm{~K}$. On the other hand, this anomaly must induce a broadening of the tunnelling spectra when the temperature decreases. 


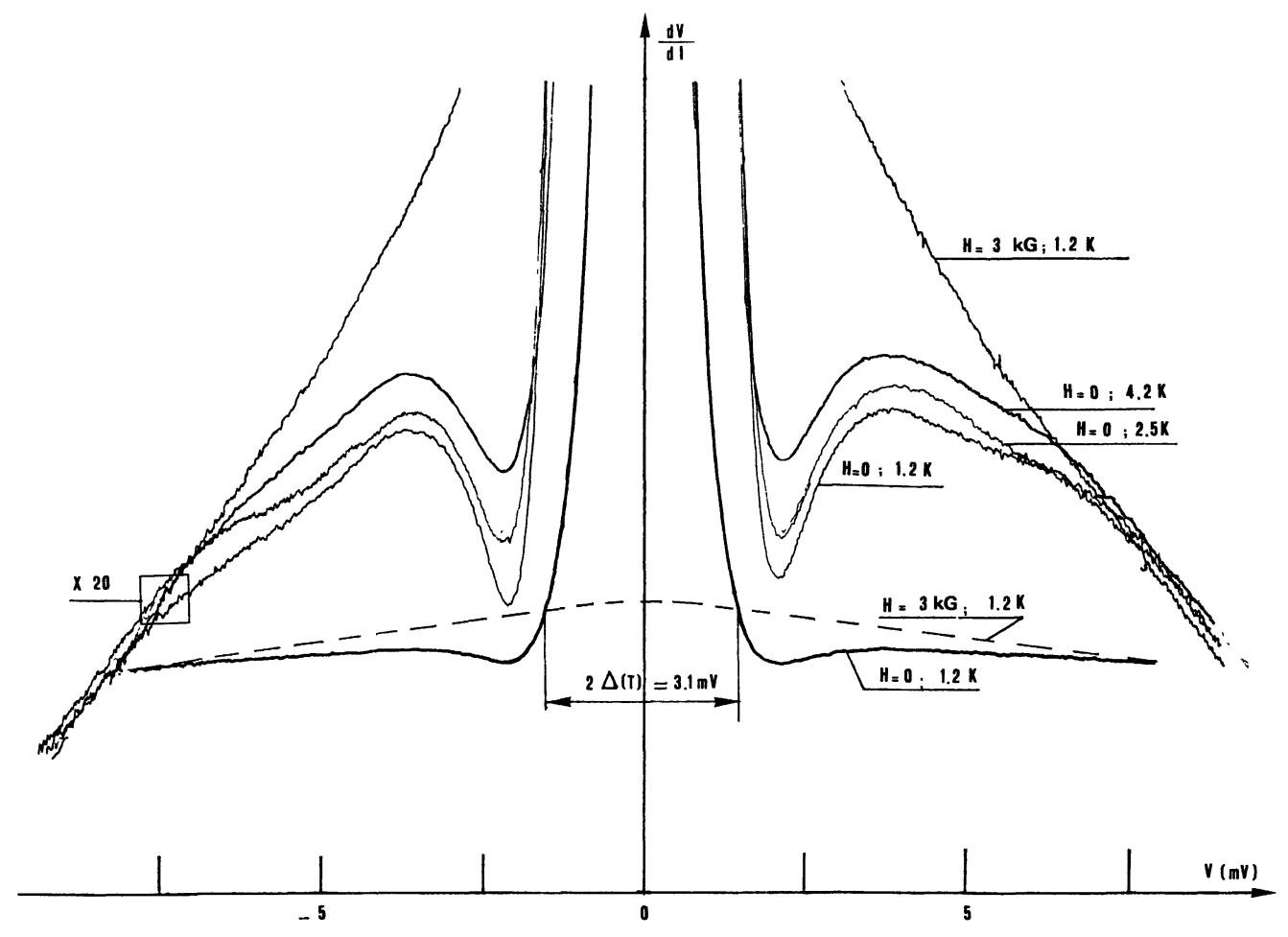

Fig. 4. - The case 2 is illustrated by this figure. With an amplification $(\times 20)$ the phonon TA-electron interaction is visible near $6 \mathrm{mV}$. With a $3 \mathrm{kG}$ magnetic field, a large zero bias anomaly subsists.

For all the identified anomalies [7], we can eliminate those due to magnetic impurities which cannot be present in the barrier in our case. On the other hand, the electron relaxation time in the junction electrodes [8] cannot explain the relatively large modification of $R=\mathrm{d} V / \mathrm{d} I$, when the temperature decreases $(\Delta R / R$ is greater than the typical value $\simeq 0.1 \%)$. We cannot nevertheless ignore the anomaly due to small particles embedded in the barrier [9]. Giaever and Zeller have shown that in such a case, a tunnelling current between the electrodes of a $M / I / M$ junction is obtained, via the embedded particles. The crossing through these intermediate sites needs an activation energy which is responsible for the resistivity peak $R=\mathrm{d} V / \mathrm{d} I$ when $V$ varies.

In our case, the only particles which may be present in the barrier are lead particles, with a critical field greater than that of bulk lead. The variation of $R=\mathrm{d} V / \mathrm{d} I$ versus the magnetic field when $H>H_{c}$ of bulk lead (Insert of figure 2) may be explained by such a situation. But we add that $T_{\mathrm{c}}$ of the particles should be nearly equal to that for bulk lead (curve 6 being flat until 7.2 K). This implies the presence of relatively large particles (dimension $>1000 \AA$ ). The broadening of the tunnelling curve when $T$ decreases, which is opposite to the evolution seen by Giaever and Zeller, might be due to an increase of the activation energy (evolution to a more symmetric barrier ?) If this were the case the absence (or the weakness) of this anomaly for temperatures greater than $6 \mathrm{~K}$ would not be clear. Moreover at a threshold temperature (always the same), around $6 \mathrm{~K}$, the activation energy must go from a negligible to an observable value.

Another possible explanation is that the perturbation of lead spectra is due to (TMTSF) ${ }_{2} \mathrm{ClO}_{4}$. This would indicate that, on one hand, the organic crystal density of states at the Fermi level decreases progressively from a threshold temperature $T>T_{\mathrm{c}}$ of (TMTSF) ${ }_{2} \mathrm{ClO}_{4}$, and on the 
other hand, that a magnetic field greater than that of bulk lead and of (TMTSF) ${ }_{2} \mathrm{ClO}_{4}$ critical field, restores progressively this density of states. Then, the hypothesis of the Orsay group [1] (existence of 1-D fluctuation superconductivity) would be sustained. Indeed, in such a case, the density of states must decrease from a threshold temperature $T>T_{\mathrm{c}}$ and a magnetic field must restore it.

Case 2. - We have an intermediate case between case 1 and case 3 described below.

Case 3. - We observe an increase around $90 \mathrm{~K}$ of $\mathrm{d} V / \mathrm{d} I(V=0)($ Fig. 6) when the temperature decreases, an absence of electron-phonon interaction, and typical curves of a $\mathrm{M} / \mathrm{I} / \mathrm{S}$ junction (Fig. 5).

These junctions are of less good quality than those of the first case. The zero bias anomaly is too strong and does not allow us to observe the effect of the electron-phonon interaction. The unusual effect described in the first case is either masked by this anomaly, or absent. In the latter case a possible explanation is that the crystal surface has been slightly but sufficiently disturbed so that any particular character due to the low dimensionality of (TMTSF) ${ }_{2} \mathrm{ClO}_{4}$ is suppressed, the metallic character being preserved.

The tunnelling spectra of (TMTSF) ${ }_{2} \mathrm{ClO}_{4} / \mathrm{I} / \mathrm{Pb}$ junction, obtained by Bando et al. [10] does not show the effect of the electron-phonon interaction. It is likely that the authors mentioned above have obtained a spectra comparable to those of our case 3, which, we think, does not allow

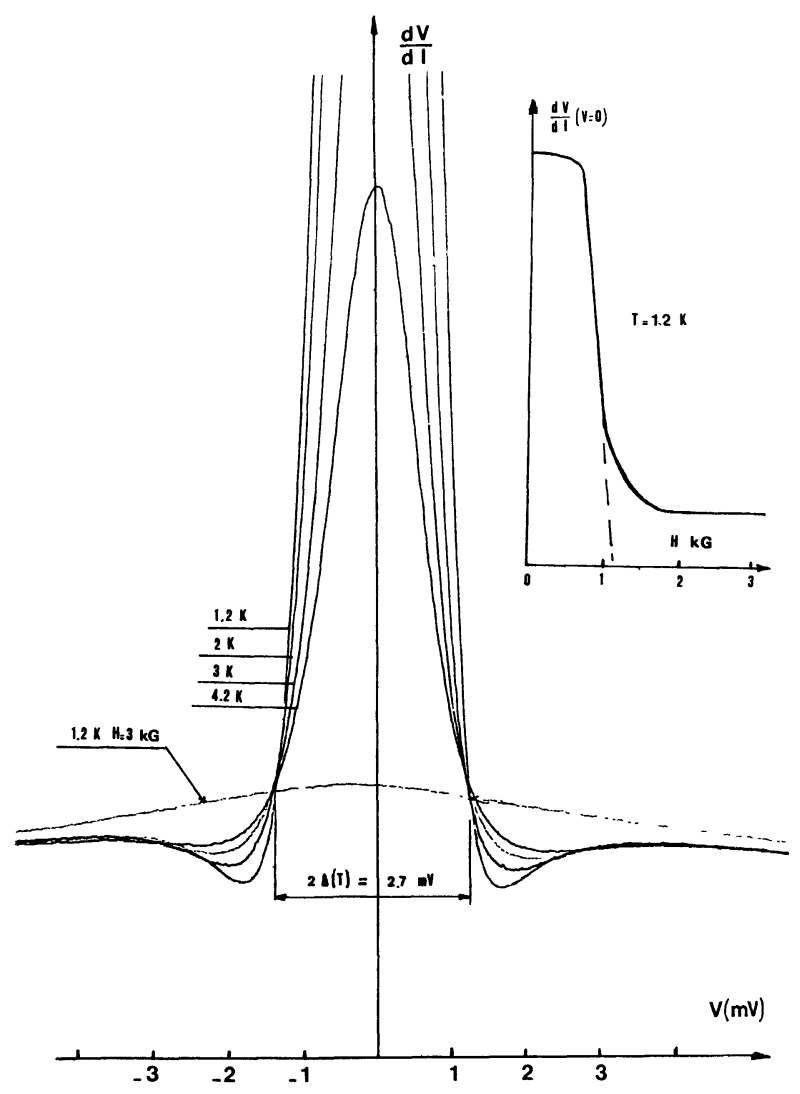

Fig. 5. - Typical curves illustrating the case 3. We have the classical $\mathrm{d} V / \mathrm{d} I$ versus bias voltage curves of $\mathrm{S} / \mathrm{I} / \mathrm{M}$ junctions. The insert shows the dependence of $\mathrm{d} V / \mathrm{d} I(V=0)$, or maximum, versus magnetic field. 


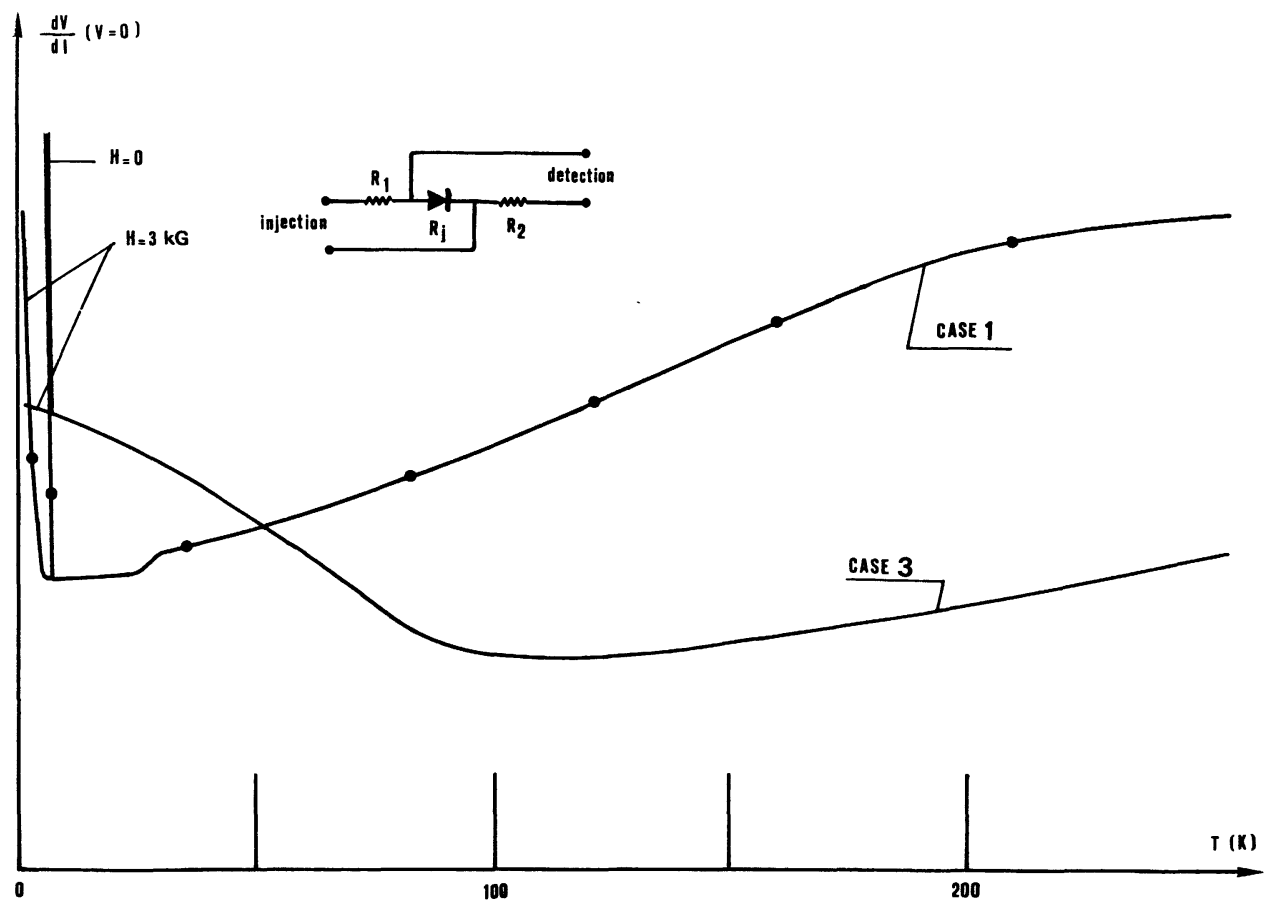

Fig. 6. - Behaviour versus temperature at null bias voltage of $\mathrm{d} V / \mathrm{d} I$ of two junctions describing the case 1 and the case 3 . In the insert we have drawn the circuit used to explain the decrease of $\mathrm{d} V / \mathrm{d} I$ versus temperature at high temperature.

fine effects to be observed, particularly those due to the possible existence of fluctuating superconductivity.

Finally it is not possible to compare our spectra with those published by Maruyama et al. [11] because these authors have not characterized the state, relaxed or quenched, of (TMTSF $)_{2} \mathrm{ClO}_{4}$.

\section{Conclusion.}

With our best junctions we have obtained a particular effect when the temperature decreases from $4.2 \mathrm{~K}$ to $1.2 \mathrm{~K}$. Our experimental results do not allow us to give a definitive explanation : have we observed an effect due to a zero bias anomaly (probably due to small particles embedded in the barrier) or to the presence of fluctuation superconductivity ? The situation will become clear when we are able to observe this effect from $T>T_{\mathrm{c}}$ of (TMTSF) ${ }_{2} \mathrm{ClO}_{4}$, in the relaxed state to $T<T_{\mathrm{c}}$. If this effect is due to the organic conductor it will be possible to obtain from the experimental results the temperature dependence of the density of states at the Fermi level and to compare it to the theoretical results of the Orsay group. This work is in progress.

Moreover, it will be interesting to obtain different spectra in the quenched or relaxed states. If quenching induces only a partial condensation (S.D.W. state) the tunnelling spectra will be approximately the same as in the relaxed state. Only a magnetic field dependence will be able to show the difference. If however the quenching induces a complete condensation, the tunnelling spectra will be comparable to those of $S / I / S^{\prime}$ junctions (but this last case is less probable). 


\section{Acknowledgments.}

We are grateful to D. Jerome who has greatly stimulated this work. We thank J. Klein, C. Bourbonnais and H. J. Schulz for many helpful discussions. We thank K. Bechgaard, A. Moradpour and J. Fabre who provided a very great number of samples.

\section{References}

[1] Jerome, D., Proceedings of the NATO Advanced Study Institute, Cambridge, U.K. 1983, Physics and Chemistry of Electrons and Ions in Condensed Matter (D. Reidel, Publ. Co.) and references therein.

[2] Rowell, J. M., in Tunneling Phenomena in Solids, Ed. by E. Burstein and S. Lundvist (Plenum Press, N.Y.) 1969, p. 273.

[3] Fournel, A., OUjIA, B., Sorbier, J. P., Proceedings of International Conference of Synthetic Metals, Abano Terme (1984), to be published.

[4] Gubser, D. U., Fuller, W. W., Poehler, T. O., Stokes, J., Cowan, D. O., Lee, M., Bloch, A. N., Proceedings of the International Conference on Low Dimensional Conductors, Boulder (Colorado). Mol. Cryst. Liq. Cryst. 79 (1982) 581.

[5] Pouget, J. P., Shirane, G., Bechgaard, K., Fabre, J. M., Phys. Rev. B 27 (1983) 5203.

[6] Takahashi, T., Jerome, D., Bechgaard, K., J. Physique Lett. 43 (1982) L-565.

[7] Wolf, E. L., Proceedings of the International Conference and Symposium on Electron Tunneling, University of Missouri, Columbia, U.S.A., 1977. Ed. by T. Wolfram (Springer-Verlag) 1978, p. 220.

[8] Trofimenkoff, P. N., Kreuzer, H. J., Wattamaniuk, W. T., Adler, J. G., Phys. Rev. Lett. 29 (1972) 597.

[9] Zeller, H. R., Giaever, I., Phys. Rev. 181 (1969) 789.

[10] Bando, H., Kajimura, K., Anzai, H., Ishiguro, T., Proceedings of the International Conference on the Physics and Chemistry of Low Dimensional Synthetic Metals (Abano Terme, Italy) 1984. L.T. 17 (Karlsruhe) 1984.

[11] Maruyama, Y., Hirosh, R., Saito, G., Hinokuchi, H., Solid State Commun. 47 (4) (1983) 273. 